\title{
Bereitschaftspotential in patients with unilateral lesions of the supplementary motor area
}

\author{
L DEECKE, * W LANG, ${ }^{*}$ H J HELLER, M HUFNAGL, H H KORNHUBER \\ From the Neurological Clinic, University of Ulm, FRG, and the Neurological Clinic, University of Vienna, \\ Austria*
}

SUMMARY In the present study, an attempt was made to examine the sensitivity of the Bereitschaftspotential (BP) preceding simple finger movement in revealing pathophysiological patterns of premovement cortical activity in patients with chronic unilateral lesions of the supplementary motor area (SMA). Usually, in healthy subjects, BP has a clear maximum in $\mathrm{Cz}$ with larger amplitudes than in Ccon (located over the motor cortex, contralateral to the performing hand). In the patients, amplitudes did not differ between $\mathrm{Cz}$ and Ccon. This effect of the lesion on BP topography, was found in movements of either side. However, intraindividual comparisons revealed that the reduction of the $\mathrm{BP}$ in $\mathrm{Cz}$ (relative to Ccon) was larger for movements contralateral to the SMA lesion than for those ipsilateral of it.

Although known since the paper by $\mathrm{C}$. and $\mathrm{O}$. Vogt, ${ }^{1}$ the supplementary motor area (SMA), located on the mesial surface of the frontal lobe between the hemispheres, has recently regained attention, after recordings of the Bereitschaftspotential (BP) or readiness potential in patients with Parkinson's disease ${ }^{2}$ and measurements of regional cerebral blood flow ${ }^{3}$ have shown that SMA is active in conjunction with voluntary movements. Based on increasing experimental data, it has been suggested by Kornhuber ${ }^{5}$ and by Deecke et al. ${ }^{6}$ that the SMA is involved in the initiation of voluntary movement and in the temporal organisation of sequential motor tasks.

In healthy subjects, the BP is widespread and can be recorded even over the hemisphere ipsilateral to unilateral movement. For finger movement, the BP has its earliest onset at the vertex $(\mathrm{Cz})$, where BP amplitude is maximum..$^{7-9}$ The independence of this generator at the fronto-central midline (presumably representing SMA) from the one in the primary motor cortex (MI) has been shown in patients with Parkinson's disease. ${ }^{2}$ Furthermore, using magnetoencephalography (MEG), the two generators, the earlier SMA and the later MI source, could be separated. ${ }^{10}$ Based on these findings it was of interest

Address for reprint requests: Prof Dr L Deecke, Neurological Clinic, University of Vienna, Lazarettgasse 14, A-1097 Wien, Austria.

Received 22 January 1987.

Accepted 25 April 1987 to evaluate pathophysiological aspects of unilateral SMA lesion by means of BP measurements.

Patients with bilateral lesions of the SMA are known to remain aspontaneous and mute. ${ }^{11}$ Acute, unilateral lesions of the SMA produce a transient "akinesia" or a lack of spontaneous activity on the contralateral side. ${ }^{1213}$ When on the left side, patients have transient problems in initiation or temporal organisation of speech. ${ }^{14} 15$ In chronic stages it is usually hard to diagnose any lack of spontaneous activity in clinical observations except for some "laziness" in the spontaneous handling of verbal material (Duffy, personal communication). In the present investigation, an attempt was made to search for signs of SMA impairment in movement initiation as investigated by the BP method.

By having the patients perform rapid right and left finger movements in consecutive counterbalanced runs, depending on the side of the SMA lesion, movements contralateral and ipsilateral to the lesion were compared in the same experiment. This comparative study was believed to answer two points of interest: (1) Are there differences in BP amplitude if movements are performed ipsilaterally or contralaterally to the side of the SMA lesion? (2) Has the BP still its maximum at the fronto-central midline $(\mathrm{Cz})$ in patients with unilateral SMA lesions as found in healthy subjects?

A preliminary report of the present data appeared as a congress abstract. ${ }^{16}$ 


\section{Method}

Twelve experiments were carried out on 12 patients, four of whom were female and eight male, mean age 53 years. Patients were selected by scanning the files of about 21,000 computerised tomograms (CTs) at Ulm Neurological University Clinic. Twenty CTs matched the following criteria of selection: CTs had to show (1) a lesion of the supplementary motor area (SMA), (2) this had to be unilateral, (3) should expand from the mantle edge to the cingulate sulcus, (4) had to be restricted to the SMA, (5) had to be solitary, and (6) patients had to be right handed. Lesions consisted of infarctions within the territory of the anterior cerebral artery, or of meningiomas of the falx, or other tumours, after operation. From the 20 patients whose CTs were taken into closer consideration, 15 agreed to be readmitted to the clinic and volunteered to participate in an experiment of 3 to 4 hours duration. In the end, only 12 patients matched our strict criteria of successful BP experiments.

The CTs were evaluated by the method of Blunk et al. ${ }^{17}$ which was extended to include high frontoparietal sections. Lesion areas in the patients' CTs were transferred to dot diagrams of nine standard CT axial matrices in a computerreadable form. Eight patients had their lesions in the right hemisphere, four had them in the left. According to the
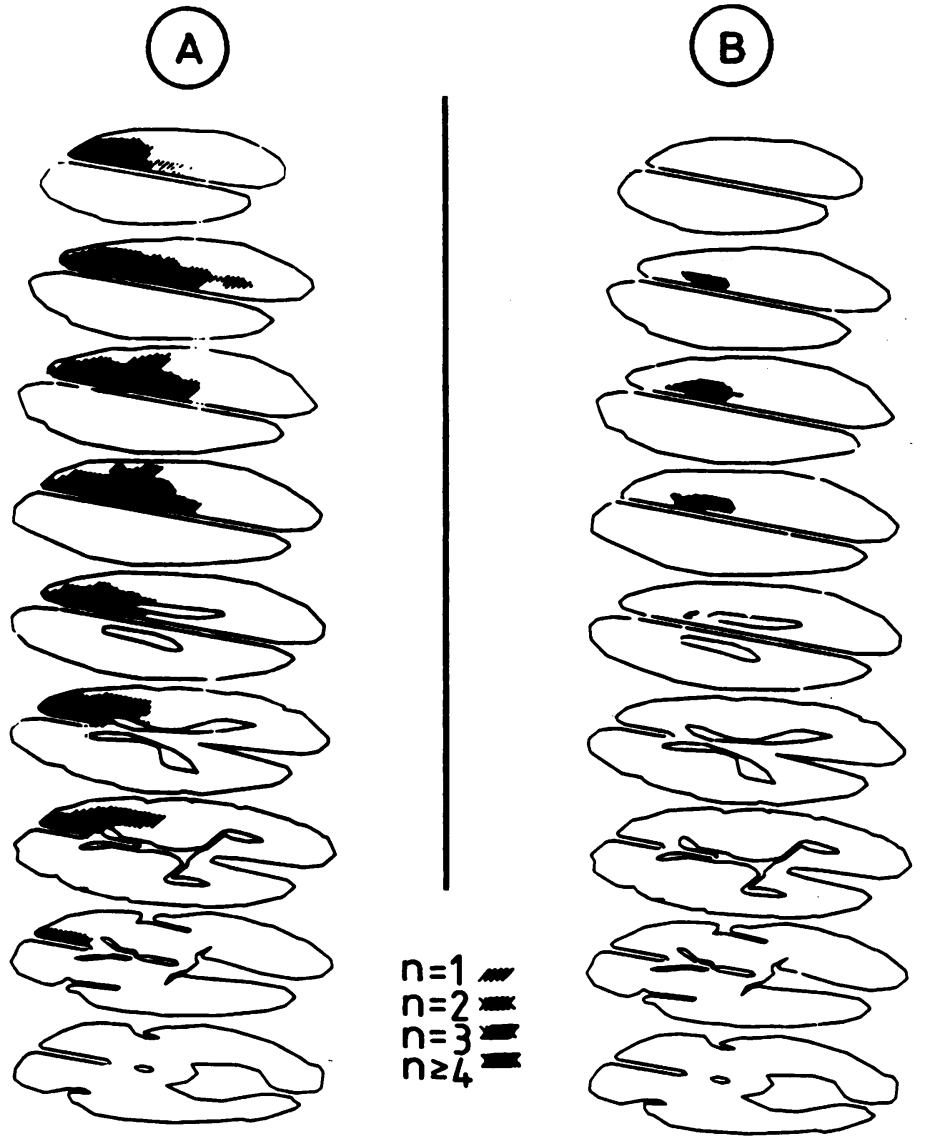

Fig 1 Part (A) gives the superimposed plot of 12 patients with unilateral SMA lesions. In (B), the common portion of all lesions is marked. mental design of the study all data were processed in terms of "affected hand" (that is, movements performed contralaterally to the SMA lesion) or of "healthy hand" (movements performed ipsilaterally to the SMA lesion). For display, all lesions were shifted to the right hemisphere: fig IA shows the superimposed CT lesions of the 12 patients and fig 1B the lesion area that was common for the 12 patients.

Handedness was assessed by a questionnaire modified after Oldfield. ${ }^{18}$ All 12 patients scored $100 \%$ dextrality and had this score already in their premorbid times. Four patients had rare Jacksonian fits, nine reported troubles of concentration or memory, three complained of headache, two had a weak hemiparesis of only the leg. The mean period between the event causing the lesion and the experiment was 4.5 years $(S D=4.53)$, the shortest latency being 14 months. On clinical observation, no differences in use of either hand other than those of handedness were found.

Patients were comfortably seated in an EEG chair in an electrically shielded quiet room. The performing hand loosely grasped the handle of a modified pistol which was mounted on the arm rest of the chair. When pulling the trigger by flexing the index finger, an electrical circuit was opened describing onset time and duration of the performance (cf. mechanogram ("Mech.") in fig 2). However, 
(A)
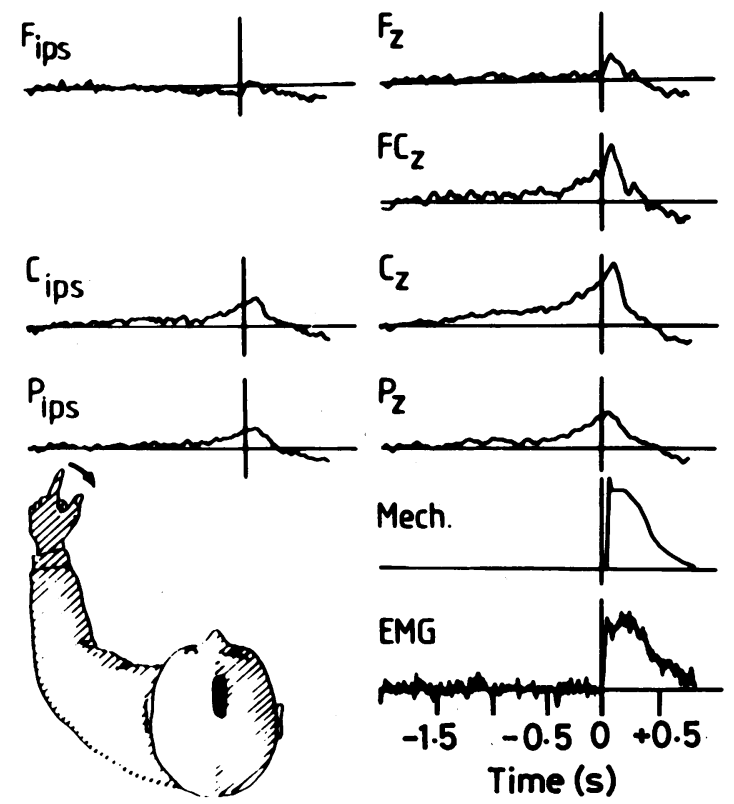

(B)

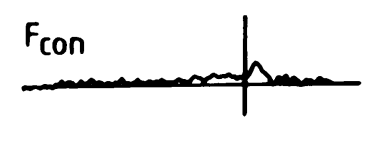

$F_{2}$
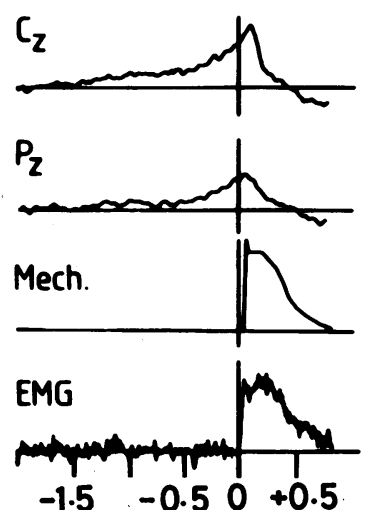

Time (s)

\section{.}
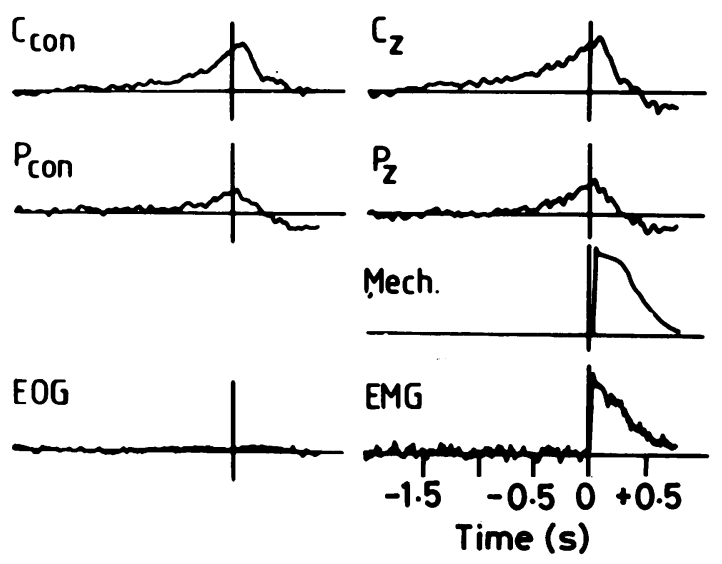
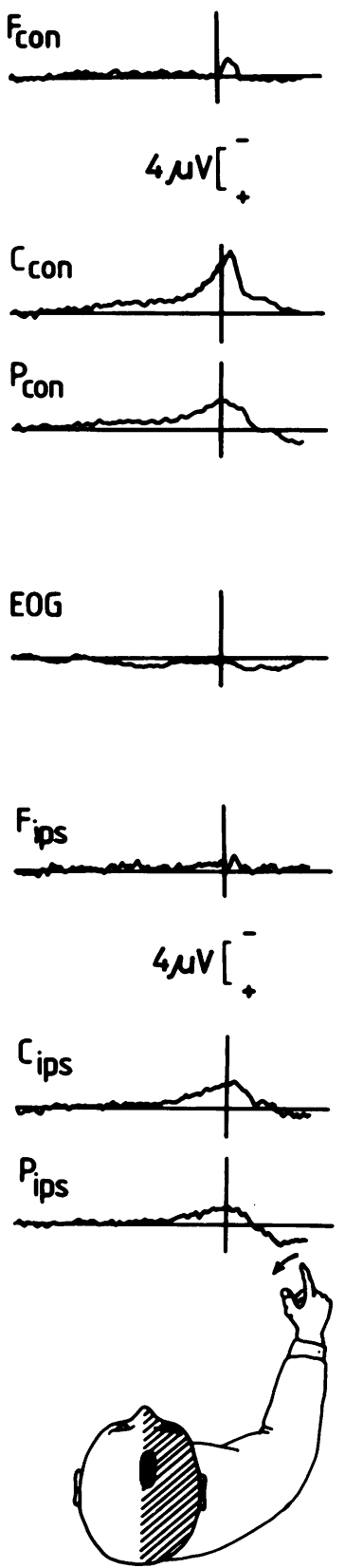

Fig 2 (A) Grand averages of the BP prior to flexions of the index finger. Movements were performed by the hand contralateral to the SMA lesion ("affected hand"). Graphs are arranged in a topographical manner. The index "con" is the abbreviation for electrode sites contralaterally located to the performing hand; "ips" means "ispsilateral" to the performing hand. Each graph represents the mean of 1536 artifactfree trials (12 Ss $\times 128$ trials). Abrupt onset of the movement seen in the rectified EMG (rEMG) of the flexor digitorum muscle, pars indicis, was used for trigger.

(B) Grand averages of the BP for movements ipsilateral to the SMA lesion ("healthy hand"). Data analysis and presentation analogous to fig $2 A$. 
movement onset for triggering $(t=0)$ was determined by the first activity in the rectified EMG (rEMG) of the flexor digitorum communis muscle, pars indicis (cf. "EMG" in fig 2). Only those trials were taken for averaging in which the rEMG has a clear-cut ascent.

Large electrodes $(16 \mathrm{~mm}$ in diameter) were affixed to the scalp using Grass EC2 cream at positions F3, Fz, F4, FCz ( $10 \%$ anterior of the vertex in order to overlie the SMA), C3, $\mathrm{Cz}$ (vertex), C4, P3, Pz, and P4. These 10 channels along with the EOG (medial upper versus lateral lower orbital rim), rEMG, and the mechanogram were averaged in an off-line procedure that automatically rejected those trials, which on-line had been marked as contaminated by artifacts (because of movements of eyes or orofacial musculature, etc.). Interelectrode impedances were kept below $1 \mathrm{k} \Omega$ in order to prevent skin potential artifacts. ${ }^{19}$

Finger flexions contralateral to the SMA lesion ("affected hand") and finger flexions ipsilateral to the SMA lesion ("healthy hand") were performed in separate runs of 64 artifact-free trials, the order of which was balanced across experiments. Each experiment consisted of four runs, bringing together the total number of 128 trials per condition.

The analysis period was 3 seconds, $2 \mathrm{~s}$ of which were pretrigger. The baseline was created by computer from the first $0.75 \mathrm{~s}$. The time constant was $2.7 \mathrm{~s}$ (EMG $0.3 \mathrm{~s}$ ) and the upper frequency limit was $70 \mathrm{~Hz}(\mathrm{EMG} 700 \mathrm{~Hz}$ ). In order to derive a single parameter for statistical tests, the mean negativity over the last $100 \mathrm{~ms}$ prior to movement onset was calculated (N-BP). For statistics, the Wilcoxon matched pairs signed rank test (including Bonferroni's correction) was used.

Lesion-induced effects on the BP were assessed by comparing the BP for movements of the "affected hand" with the BP for movements of the "healthy hand". The following parameters were used for these comparisons: $\mathrm{N}-\mathrm{BP}$, recorded in the different leads, and $\mathrm{dN}-\mathrm{BP}_{\mathrm{c}}$, difference between $\mathrm{Cz}$ and $\mathrm{Ccon}$ (Ccon: position over the motor cortex hand area contralateral to the performing hand) and $\mathrm{dN}-\mathrm{BP}_{\mathrm{FCz}_{\mathrm{z}}}$, difference between $\mathrm{FCz}$ and Ccon, in order to quantify BP topography.

Reasoning from previous investigations, ${ }^{2}$ it was believed that activity from the SMA can be best recorded from leads over the fronto-central midline $(\mathrm{FCz}$ and $\mathrm{Cz}$ ). The parameters $\mathrm{dN}-\mathrm{BP}_{\mathrm{c}}$ and $\mathrm{dN}-\mathrm{BP}_{\mathrm{FCz}}$ were supposed to be adequate for quantifying a relative $\mathrm{BP}$ reduction over the frontocentral midline since it is known from literature that in healthy human subjects a BP maximum can consistently be found at $\mathrm{Cz}$, which implies that the $\mathrm{BP}$ in $\mathrm{Cz}$ is larger than the one in Ccon. ${ }^{20-24}$

\section{Results}

In central and parietal recordings, a surface negative Bereitschaftspotential (BP) preceded the finger movements which were performed either contralaterally or ipsilaterally to the SMA lesion (fig 2A, B).

Comparing the two conditions, the mean negativity during the last $100 \mathrm{~ms}$ prior to the onset of the movement (N-BP) revealed hardly any difference. In particular, no significant differences could be found in $\mathrm{FCz}$ and $\mathrm{Cz}$ : In $\mathrm{FCz}$, the amplitudes were $-2.46 \mu \mathrm{V}$
(SE 0.61) for the "affected hand" and $-2.62 \mu \mathrm{V}$ (SE 0.62 ) for the "healthy hand". In $\mathrm{Cz}$, the amplitudes were $-3.53 \mu \mathrm{V}$ (SE 0.58) for the "affected hand" and $3.76 \mu \mathrm{V}(0.68)$ for the "healthy hand".

In the two conditions, "healthy hand" and "affected hand", the largest amplitudes of N-BP were obtained in $\mathrm{Cz}$ and $\mathrm{Ccon}$. $\mathrm{dN}-\mathrm{BP}_{\mathrm{c}}$ was significant neither for movements of the "healthy hand" nor for those of the "affected hand", that is, a significant BP maximum in $\mathrm{Cz}$ was missing in both conditions. This relative reduction of the $\mathrm{BP}$ over the fronto-central midline, which represents an effect of the SMA lesion was larger for movements of the "affected hand" than it was for those of the "healthy hand"; N-BP for movements of the "healthy hand" averaged -3.76 $\mu \mathrm{V}$ (SE 0.68) in $\mathrm{Cz}$ and $-3.45 \mu \mathrm{V}$ (SE 0.42) in Ccon, whereas N-BP for movements of the "affected hand" averaged $-3.53 \mu \mathrm{V}$ (SE 0.58 ) in $\mathrm{Cz}$ but as much as $-3.89 \mu \mathrm{V}$ (SE 0.47) in Ccon. Within-subject differences of $\mathrm{dN}-\mathrm{BP}_{\mathrm{c}}$ surpassed the level of significance $(p<0.05)$.

$\mathrm{dN}-\mathrm{BP}_{\mathrm{FC}_{2}}$ was significant for movements contralateral to the SMA lesion with larger BP amplitudes in Ccon $(p<0.05)$. The reduction of BP amplitudes in $\mathrm{FCz}$ (relative to Ccon) was larger in movements of the "affected hand" than it was in those of the "healthy hand" $(p<0.05)$.

\section{Discussion}

Two results seem to be of interest: (1) In patients with unilateral lesions of the SMA, a BP maximum at $\mathrm{CZ}$ is missing in movements of either side. (2) The relative reduction of the BP amplitude in the fronto-central midline $(\mathrm{FCz}$ and $\mathrm{Cz})$ as compared with Ccon is larger for movements contralateral to the SMA lesion than for those ipsilateral of it.

Owing to the first result, unilateral SMA lesions affect, to some extent, BP topography in movements of either side. This finding may support the concept that each SMA is involved in movements of either side of the body, at least in simple movements such as flexions of the finger. In our cases, the remaining SMA might control both MI areas, the contralateral one via known connections through the corpus callosum which, according to the CTs, remained intact in our subjects. There is evidence in the literature for this assumption: In monkeys, SMA neurons showed modulation of their activity during particular movements and did so regardless of whether the contralateral or the ipsilateral arm was used. ${ }^{25}$ In humans, measurements of the regional cerebral blood flow show bihemispheric activation of the SMA and basal genglia with unilateral movements, whereas MI activation is only contralateral. ${ }^{26}$.

The second result can be taken as evidence that, in 
unilateral finger movement, the contralateral SMA contributes a little bit more to the initiation of a movement. Consequently, for movements contralateral to the SMA lesion, a larger BP reduction over the fronto-central midline is found as compared with movements ipsilateral to the lesion.

Recently, it has been shown that the BP over the fronto-central midline increased when single movements were performed simultaneously or sequentially. It has been suggested that this additional negativity (when comparing it with the BP prior to a single movement) reflects a greater activation of the supplementary motor area. ${ }^{24}$ It might well be that the compensation of unilateral SMA lesions holds only for simple movements and that the employment of motor tasks with increasing difficulty could reveal SMA deficits in clinical tests as well as in BP studies. A recent case study of Dick et $a l .{ }^{27}$ substantiates these assumptions by demonstrating intact simple movements but disturbed simultaneous or sequential movements in a patient with a unilateral SMA lesion.

The search for the function proper of the SMA and for those BP paradigms that are discriminant is not only of interest for patients with SMA lesions but also for patients with Parkinson's disease since there is increasing evidence that some of the motor abnormalities seen in Parkinson's disease might be understood in terms of relations between the basal ganglia and the supplementary motor area as already pointed out by O. Förster ${ }^{28}$ in 1936 when describing what he called "pallidumähnliches Frontalhirnsyndrom nach Läsion von area $6 \mathrm{a} \beta$ " (pallidum-like syndrome of the frontal lobes caused by lesions of area $6 \mathrm{a} \beta$ ) and as substantiated in previous investigations. ${ }^{272930}$

This work was supported by the Deutsche Forschungsgemeinschaft (De 302/3-1).

References

1 Vogt C, Vogt O. Allgemeinere Ergebnisse unserer Hirnforschung 4. Die physiologische Bedeutung der architektonischen Rindenfelderung auf Grund neuer Rindenreizungen. Journal für Psychologie und Neurologie (Leipzig) 1919;25:339-462.

2 Deecke L, Kornhuber HH. An electrical sign of participation of the mesial "supplementary" motor cortex in human voluntary finger movements. Brain Res 1978;159:473-6.

3 Lassen NA, Ingvar DH, Skinhoj E. Brain function and blood flow. Sci Am 1978;239:62-71.

4 Roland PE, Larsen B, Lassen NA, Skinhoj E. Supplementary motor area and other cortical areas in the organization of voluntary movements in man. J Neurophysiol 1980;43:118-36.

5 Kornhuber $\mathrm{HH}$. Attention, readiness for action and the stages of voluntary decision-some electrophysiological correlates in man. In: Creutzfeldt $O$, Schmidt RF, and Willis WD, eds. Sensory-motor integration in the nervous system. Exp Brain Res Suppl 1984;9:420-9.

6 Deecke L, Kornhuber HH, Lang W, Lang M, Schreiber H. Timing function of the frontal cortex in sequential motor and learning tasks. Human Neurobiol 1985;4:143-54.

7 Kornhuber $\mathbf{H H}$, Deecke L. Hirnpotentialänderungen bei Willkürbewegungen und passiven Bewegungen des Menschen: Bereitschaftspotential und reafferente Potentiale. Pfügers Arch 1965;284:1-17.

8 Deecke L, Scheid P, Kornhuber HH. Distribution of readiness potential, pre-motion positivity and motor potential of the human cerebral cortex preceding voluntary finger movements. Exp Brain Res 1969;7:158-68.

9 Deecke L, Grözinger B, Kornhuber HH. Voluntary finger movement in man: Cerebral potentials and theory. Biol Cybern 1976;23:99-119.

10 Deecke L, Boschert J, Brickett P, Weinberg H. Magnetoencephalographic evidence for possible supplementary motor area participation in human voluntary movement. In: Weinberg H, Stroink G, Katila T, eds. Biomagnetism: Application and Theory. New York: Pergamon Press, 1985:369-72.

11 Beringer K. Antriebschwund mit erhaltener Fremdanregbarkeit bei beiderseitiger frontaler Marklagerschädigung. $Z$ Neurol 1944;176:10-13

12 Penfield W, Jasper H. Epilepsy and the functional anatomy of the human brain. Boston: Little, Brown, 1954:100.

13 Laplane DJ, Talairach V, Meininger V, Bancaud J, Orgogozo JM. Clinical consequences of cortectomies involving the supplementary motor area in man. J Neurol Sci 1977;34:301-14.

14 Jonas $\mathrm{S}$. The supplementary motor region and speech emission. $J$ Commun Disord 1981;14:349-73.

15 Rubens AB. Aphasia with infarction in the territory of the anterior cerebral artery. Cortex 1975;11:239-50.

16 Heller WJ, Lang W, Hufnagl M, Deecke L, Kornhuber HH. Das Bereitschaftspotential bei unilateraler chronischer Läsion der supplementär-motorischen Area (SMA). In: Gänshirt H, Berlit P, Haack G, eds. Erkrankungen und Nervensystem, Neurotoxikologie, Probleme des Hirntodes. Berlin: SpringerVerlag, 1985:891-4.

17 Blunk R, De Blesser R, Willmes K, Zeumer H. A refined method to relate morphological and functional aspects of aphasia. Eur Neurol 1981;20:69-79.

18 Oldfield RC. The assessment and analysis of handedness. The Edinburgh Inventory. Neuropsychologia 1971;9:97-113.

19 Picton TW, Hillyard SA. Cephalic skin potentials in electroencephalography. Electroencephalogr and Clin Neurophysiol 1972;33:419-24.

20 Kristeva R, Keller E, Deecke L, Kornhuber HH. Cerebral potentials preceding unilateral and bilateral simultaneous finger movements. Electroencephalogr Clin Neurophysio 1979;47:229-38.

21 Schreiber H, Lang M, Lang W, Kornhuber A, Heise B, Keidel M Deecke L, Kornhuber HH. Frontal hemispheric differences of the Bereitschaftspotential associated with writing and drawing. Hum Neurobiol 1983;2:197-202.

22 Lang W, Lang M, Heise B, Deecke L, Kornhuber HH. Brain potentials related to voluntary hand tracking, motivation and attention. Hum Neurobiol 1984;3:235-40.

23 Barrett G, Shibasaki H, Neshige R. Cortical potentials preceding voluntary movement: evidence for three periods of preparation in man. Electroencephalogr Clin Neurophysiol 1986;63:327-39.

24 Benecke R, Dick JPR, Rothwell JC, Day BL, Marsden CD Increase of the Bereitschaftspotential in simultaneous and sequential movements. Neurosci Let 1985;62:347-52.

25 Brinkman C, Porter R. Supplementary motor area in the monkey: activity of neurons during performance of a learned motor task. J Neurophysiol 1978;42:681-709.

26 Roland PE, Meyer E, Shibasaki SHI, Yamamoto JL, Thompson CJ. Regional cerebral blood flow changes in cortex and basal ganglia during voluntary movements in normal human volunteers. $J$ Neurophysiol 1982;48:467-80.

27 Dick JPR, Benecke R, Rothwell JC, Day BL, Marsden CD Simple and complex movements in a patient with infarction of the right supplementary motor area. Movement Disor 1986;1:255-66.

28 Förster $O$. Motorische Felder und Bahnen. In: Bumke $O$ Förster O, Hrsg. Handbuch der Neurologie IV. Berlin: Springer, 1936:298-9.

29 Schell GR, Strick PL. The origin of thalamic inputs to the arcuate premotor and supplementary motor areas. $J$ Neurosci 1984;4:539-60

30 Alexander GE, DeLong MR, Strick PL. Parallel organization of functionally segregated circuits linking basal ganglia and cortex. Ann Rev Neurosci 1986;9:357-81. 